\title{
Responsiveness of the SF-36 Questionnaire to the Treatment Outcome: A Comparison of the Mental and the Physical Patients
}

\author{
Marzieh Atabakhsh ${ }^{1} \&$ Mehrdad Mazaheri ${ }^{2}$ \\ ${ }^{1}$ MSc student in General Psychology, University of Sistan and Baluchestan, Iran \\ ${ }^{2}$ Associate professor of psychology, Ferdowsi University of Mashhad, University of Sistan and Baluchestan, \\ Iran \\ Correspondence: Mehrdad Mazaheri, Associate professor of psychology, Ferdowsi University of Mashhad, \\ University of Sistan and Baluchestan, Iran. E-mail: M.Mazaheri@um.ac.ir \\ Received: March 10, 2016 \\ Accepted: March 27, 2016 \\ Online Published: April 10, 2016 \\ doi:10.5539/mas.v10n6p183 \\ URL: http://dx.doi.org/10.5539/mas.v10n6p183
}

\begin{abstract}
Background: The main aim of the current paper was to study the level of the SF-36 sensitivity to the treatment outcome between mental and physical patients.

Method: A random sample of 40 physical patients (Heart, Pulmonary, Kidney, Diabetes, and Rheumatism) as well as 40 mental patients (Depression, Obsession, Schizophrenia, and Psychosis) were asked to fill out the SF-36 questionnaire three times at intervals of 10-15 days. The independent as well as paired sample t-test statistic was used to analysis data. All analyses were conducted using SPSS statistical software (version 17.0; SPSS).

Results: Our findings indicated that there is a significant increase in mean score of different domain of SF'36 questionnaire, for both physical and mental patients, as they showed an improvement on their current health status. In sum, our results can provide more psychometric evidence for sf-36 sensitivity to treatment process in an Iranian sample of physical and mental patients.
\end{abstract}

Keywords: welfare, life quality, physical/mental disorders, sf-36 questionnaire

\section{Introduction}

The theoretical definitions of "quality of life" and some related concepts such as; "well - being", " happiness", "life satisfaction" and "good life" have preoccupied a wide range of disciplines, dating far back to Aristotle (384-19 BC) and early Greek philosophy (Bowling, 2001). Aristotle, using the Greek eudaimonia ( a concept which for Aristotle meant having an understanding of the best way to live one's life), which is commonly translated as 'happiness', affirms that the quality of life is highly relative: it means different things to different people, and conditions for happiness vary according to a person's current condition. Happiness for Aristotle was the product of activities directed towards clearly defined goals which inform our whole life rather than being simply short-term (Chang, Killingworth, \& Noaln., 1997).

In relation to health, quality of life is defined in terms of difference between reality, or perception of reality, and expectations (Calman 1984). Quality of life has also been referred to as an affective response to one's role situation and values (Andrews and Withey, 1976). The World Health Organisation (WHO) has defined "Quality Of Life" as "an individual's perception of their position in life in the context of the culture and value systems in which they live and in relation to their goals, expectations, standards and concerns" (WHO, 1996). The WHO states that quality of life is affected by an interaction of the individual's health, mental state, spirituality, relationship and elements of their environment (WHOQOL.BREF, 1996).

It is now recognized that quality of life extends beyond a strict medical discourse into areas such as sociology, psychology, environmental studies, social work and social policy, just to name a few. In the 1960s, social scientists became more interested in the issue of quality of living, and particularly in the relationship between economic and social indicators of life quality on one hand, and the subjective evaluation of these circumstances on the other (Snoek, 2000). Social scientist for quality of life definition have focused on objective (e.g. Income, housing, educational level) or subjective (e.g. happiness, life satisfaction, wellbeing) components of quality of life (Bowling, 2001). 
In quality of life research, there is a classic distinction between objective and subjective quality of life. 'Objective' quality-of-life is the degree to which living-conditions meet observable criteria of the good life and subjective' quality of life is how people appreciate their life personally (Veenhoven, 1996). Quality of life has been defined more subjectively in terms of individual's own evaluations of their life experiences (Campbell et al. 1976, Andrews \& Withey 1976). Andrews (1974) considered it as the extent to which pleasure and satisfaction characterize human existence. Oleson (1990) believes that Quality of life is an individual's satisfaction or happiness with life in domains he or she considers important. However, some researchers in definition quality of life consider the concept only in terms of objective indicators. For example, Eblen and Eblen (1994) consider the quality of life as a description and evaluation of the nature or conditions of life (Eblen \& Eblen, 1994).

There is some evidence showing that the sf-36 is a valid and reliable tools for measuring health quality in patients with renal replacement (Gómez-Besteiro, Santiago-Pérez; Alonso-Hernández, Valdés-Cañedo, Álvarez 2004). Longitudinal assessment of sf-36 in patients with kidney stone suggested that the lack of great changes in sf-36, despite changes in the place of kidney stone, indicates that sf-36 may not be an appropriate tool to show renal stone patients' quality of life. (Donnally Lii et al, 2011). Results of a research to compare short-form musculoskeletal function assessment and sf-36 for identifying different groups of patients' functioning improvement after ankle setback showed that both muscle function test and sf-36 are able to assess patients' overall health and both are able to identify patients with serious difficulties in organ function improvement (Obremskey, Brown, Driver, Douglas , 2007 ). Dougherty, Dewhurst, Nichol, Spertus ( 1998 ) compared Seattle Angina questionnaire (SAQ), short-form health sf-36 questionnaire and the third version of cardiac symptoms of quality of life and showed that differences in severity of angina were related to every single SAQ subscale and also to the chosen sf-36 subscales.

The main aim of the current paper was to study the level of the SF-36 sensitivity to the treatment outcome between mental and physical patients.

\section{Method}

A random sample of 40 physical patients (Heart, Pulmonary, Kidney, Diabetes, and Rheumatism) as well as 40 mental patients (Depression, Obsession, Schizophrenia, and Psychosis) were asked to fill out the SF-36 questionnaire three times at intervals of 10-15 days. The independent as well as paired sample t-test statistic was used to analysis data. All analyses were conducted using SPSS statistical software (SPSS-20).

Sf-36 questionnaire is one of the specifically designed tools to measure health related quality of life in patients and it is used by researchers around the world. Scores of the questionnaire items describe health through two general physical/mental dimensions. Mental health dimension consists of scales including welfare, social functioning, vitality, emotion restrictions, and mental health. (Ware, gandek, 1998 ).

\section{Findings}

Some descriptive statistics for physical patients (including; means and standard deviations) for the two sub-scales of physical and mental health as well as SF-36 total score obtained from three measurement stages (at intervals of 10-15 days) are presented in the Table 1 .

Table 1. Descriptive statistics for three measured variables (Physical Patients)

\begin{tabular}{llll}
\hline Stage & Scale & Mean & SD \\
\hline \multirow{3}{*}{ I } & Physical health & $\mathbf{2 1 / 2 2}$ & $\mathbf{7 / 0 6}$ \\
& Mental health & $\mathbf{2 9 / 8 0}$ & $\mathbf{1 1 / 9 4}$ \\
& Total score SF-36 & $\mathbf{2 5 / 1 0}$ & $\mathbf{8 / 5 9}$ \\
II & Physical health & $\mathbf{4 0 / 6 0}$ & $\mathbf{1 0} / \mathbf{1 6}$ \\
& Mental health & $\mathbf{5 0 / 8 2}$ & $\mathbf{1 1 / 8 8}$ \\
& Total score SF-36 & $\mathbf{4 5 / 6 0}$ & $\mathbf{1 0 / 0 4}$ \\
& Physical health & $\mathbf{6 0 / 2 5}$ & $\mathbf{1 0} / \mathbf{4 2}$ \\
III & Mental health & $\mathbf{6 5 / 6 5}$ & $\mathbf{9 / 2 3}$ \\
& Total score SF-36 & $\mathbf{6 3 / 5 2}$ & $\mathbf{9 / 2 9}$ \\
\hline
\end{tabular}

As Table 1 shows, the mean of the all three measured variable (two sub-scales of physical and mental health as well as SF-36 total score) used to increase through the first to the third measurement stage. In order to find whether these differences between all compared means are statistically significant or not, the t-test for paired 
sample test were used and the results for all three variables are presented separately in the Table 2 .

Table 2. Paired samle t test to compare means (Physical patients)

\begin{tabular}{|c|c|c|c|c|c|c|}
\hline Variable & & Stages & $\mathrm{t}$ & DF & Sig. & $\begin{array}{l}\text { Mean } \\
\text { Difference }\end{array}$ \\
\hline \multirow{3}{*}{$\begin{array}{l}\text { Physical } \\
\text { health }\end{array}$} & I & II & -12.83 & 39 & 0.001 & -19.37 \\
\hline & I & III & -22.57 & 39 & 0.001 & -39.02 \\
\hline & II & III & -13.21 & 39 & 0.001 & -19.65 \\
\hline \multirow{3}{*}{ Mental health } & $\mathrm{I}$ & II & -11.01 & 39 & 0.001 & -21.02 \\
\hline & I & III & -20.71 & 39 & 0.001 & -35.85 \\
\hline & II & III & -9.59 & 39 & 0.001 & -14.82 \\
\hline \multirow{3}{*}{$\begin{array}{l}\text { SF36 } \\
\text { Total score }\end{array}$} & I & II & -12.24 & 39 & 0.001 & -20.50 \\
\hline & I & III & -22.91 & 39 & 0.001 & -38.42 \\
\hline & II & III & -12.81 & 39 & 0.001 & -17.92 \\
\hline
\end{tabular}

As seen in Table 2, significant differences were found between all compared means obtained from three measurement stages. It means that as physical patients are going to show improvement in their health status their quality of life scores is going to increase. In the other word the sf-36 score is sensitive to the health status change for both mental and physical patients.

The same analysis as the physical patients has been done for mental patients.

Some descriptive statistics for mental patients (including; means and standard deviations) for the two sub-scales of physical and mental health as well as SF-36 total score obtained from three measurement stages (at intervals of 10-15 days) are presented in the Table 3 .

Table 3. Descriptive statistics for three measured variables (Mental Patients)

\begin{tabular}{llll}
\hline Stage & Scale & Mean & SD \\
\hline \multirow{2}{*}{ I } & Physical health & 42.95 & 13.85 \\
& Mental health & 25.92 & 9.68 \\
& Total score SF-36 & 36.47 & 10.01 \\
& Physical health & 57.25 & 14.20 \\
II & Mental health & 41.10 & 10.24 \\
& Total score SF-36 & 50.47 & 11.50 \\
& Physical health & 74.75 & 9.03 \\
III & Mental health & 59.35 & 11.16 \\
& Total score SF-36 & 68.95 & 8.31 \\
\hline
\end{tabular}

As Table 3 shows, for all measured variable, an increase in mean rating were found through the first to the third measurement stage. Table 4 is presented to show the results of the paired samples t-test to compare score mean for each variable throuth three measurement stages.

Table 4. Paired sample t test to compare means (Mental patients)

\begin{tabular}{|c|c|c|c|c|c|c|}
\hline Variable & \multicolumn{2}{|c|}{ Compared Stages } & $\mathrm{t}$ & DF & Sig. & $\begin{array}{l}\text { Mean } \\
\text { Difference }\end{array}$ \\
\hline Physical & I & II & -7.06 & 39 & 0.001 & -14.30 \\
\hline health & I & III & -13.84 & 39 & 0.001 & -31.80 \\
\hline & II & III & -8.47 & 39 & 0.001 & -17.50 \\
\hline Mental health & I & II & -9.19 & 39 & 0.001 & -15.17 \\
\hline & I & III & -17.62 & 39 & 0.001 & -33.42 \\
\hline
\end{tabular}




\begin{tabular}{lllllll}
\hline & II & III & -9.33 & 39 & 0.001 & -18.25 \\
SF36 & I & II & -9.58 & 39 & 0.001 & -14.00 \\
Total score & I & III & -16.08 & 39 & 0.001 & -32.74 \\
& II & III & -9.63 & 39 & 0.001 & -18.47 \\
\hline
\end{tabular}

As Table 4 shows, significant differences were found between all compared means obtained from three measurement stages. It means that as mental patients are going to show improvement in their health status their quality of life scores is going to increase.

\section{Discussion}

The main aim of the current paper was to study the level of the SF-36 sensitivity to the treatment outcome between mental and physical patients. In a study designed to compare sf-36 and short musculoskeletal function assessment questionnaire for identifying various groups of patients indicated that both of these tools are able to assess overall patients health and able to identify patients with major difficulties in improving organ efficacy. (Obremsky ,Brown ,Driver and Douglas,200). In a study to determine the relationship between the quality of life measured by questionnaire sf-36 and nutrition, hospitalization, and mortality in hemodialysis, the results showed that there is is a significant relation ship between scores of precedent sf-36 body mass index, and the body fat. Probability of hospitalization was also significantly correlated to sf-36 total score and its two major dimensions. They also found that sf-36 two major dimensions had the highest predictive rate of mortality. In general, results from this study indicated that in MHO patients, sf-36 seems to be associated with nutritional status, anemia (low blood), and clinical outcomes including hospitalization and mortality risk. Evidences from the research suggest that $\mathrm{sf}-36$ predicts that patients with obesity are at greater risk of mortality during dialysis. (Kalantarzadeh, Kopple , Block, and Humphreys, 2001). Reulen et al (2006) in a research aimed to assess sf-36 for the status of treated survivors of childhood cancer in a sample of 10198 adults cured from childhood cancer, observed that scores of physical health scores are highly correlated to physical health concise scale scores, However, it is of a poor relationship with mental health concise scale scores. Mental health and emotional limitation rule scale were highly associated with MCS scale scores but of a poor relationship with PCS scale scores. Moreover, general health perception scores, energy, vitality, social activity were in moderate to strong association with the both scales.

In sum, the results of the present paper can provide more evidences for sf-36 sensitivity to treatment process efficacy in an Iranian sample of mental/ physical patients.

\section{References}

Andrews, F. M. (1974) Social indicators of perceived life quality. Soc Indic Res 1:279-99. Aristotle. Ethica Nicomachea, Traditional Bekker pagination 1095 a13-b6.

Andrews, F. M., \& Withey, S. B. (1976). Social Indicators of Well-being: Americans' Perceptions of Life Quality. New York: Plenum Press.

Bowling, A. (2001). Measuring disease: a review of disease-specific quality of life measurement scales, Open University press.

Callegari, A., Michelini, I., Sguazzin, C., Catona, A., \& Klersy, C. (2005). Efficacy of the SF-36 Questionnaire in Identifying Obese Patients with Psychological Discomfort. Obesity Surgery, 254-260.

Callegari, A., Michelini, I., Sguazzin, C., Catona, A., \& Klersy, C. (2005). Efficacy of the SF-36 Questionnaire in Identifying Obese Patients with Psychological Discomfort. Obesity Surgery, 254-260.

Calman, K. C. (1984). Quality of life in cancer patients . A hypothesis. Journal of Medical Ethics, 10, 124-127.

Campbell, A., Converse, P. E., \& Rogers, W. L. (1976). The Quality of American Life: Perceptions, Evaluations, and Satisfactions. New York: Russel Sage Foundation.

Chang, M. C., Killingworth, A., \& Noaln, P. (1997) A critique of the concept of quality of life. International Journal of Health Care Quality Assurance, 10(2), 80-84.

Donnally, L., Gupta, C. J., Bensalah, K., Tuncel, A., Raman, J., Pearle, M. S., \& Lotan, Y. (2011). Longitudinal evaluation of the SF-36 quality of life questionnaire in patients with kidney stones. Urological Research, 39, 141-146.

Dougherty, C. M., Dewhurst, T., Nichol, W. P., \& Spertu, J. A. (1998). Comparison of Three Quality of Life Instruments in Stable Angina Pectoris: Seattle Angina Questionnaire, Short Form Health Survey (SF-36), 
and Quality of Life Index-Cardiac Version III. J. Clin Epidemiol, 51(7), 569-575.

Eblen, R. A., \& Eblen, W. (1994). The Encyclopedia of the Environment Houghton Mifflin Company, Boston.

Gómez-Besteiro, M., M Inmaculada., Santiago-Pérez, M., Isolina, Alonso-Hernández, Á., Valdés-Cañedo, F., \& Rebollo-Álvarez, P. (2004). Validity and Reliability of the SF-36 Questionnaire in Patients on the Waiting List for a Kidney Transplant and Transplant Patients. American Journal of Nephrology, 24(3).

Kalantar-Zadeh, K. D., Kopple, J., Block, G. H., \& Humphreys, M. (2001). Association Among SF36 Quality of Life Measures and Nutrition, Hospitalization, and Mortality in Hemodialysis. American Society of Nephrology, 84-96.

Obremskey, W. T., Brown, O., Driver, R., \& Dirschl, D. (2007). Comparison of SF-36 and Short Musculoskeletal. Functional Assessment in Recovery From Fixation of Unstable Ankle Fractures, 30(2), 145-152.

Oleson, M. (1990). Subjectively perceived quality of life. Image, 22,187-190.

Reulen, C., Raoul, P., Zeegers, M., Jenkinson, C., R Lancashire, E. L., Winter, D. E., \& Jenney, M. M., \& Hawkins, M. (2006). The use of the SF-36 questionnaire in adult survivors of childhood cancer: evaluation of data quality, score reliability, and scaling assumptions. Health and Quality of Life Outcomes, 145-152.

Snoek, F. J. (2000). Quality of Life: A Closer Look at Measuring Patients' Well-Being. Diabetes Spectrum, 13, 24.

Veenhoven, R. (1996). Developments in Satisfaction Research. Social Indicators Research, 37, 1-46.

Ware, J. E., \& Gandek, B. (1998). Overview of the SF-36 Health Survey and the International Quality of Life Assessment (IQOLA) Project. Journal of Clinical Epidemiology, 51, 903-12

Whoqol, B. (1996). Introduction, Administration, Scoring and Generic Version of the assessment. (World Health Organization, Geneva)

\section{Copyrights}

Copyright for this article is retained by the author(s), with first publication rights granted to the journal.

This is an open-access article distributed under the terms and conditions of the Creative Commons Attribution license (http://creativecommons.org/licenses/by/3.0/). 